\title{
BMJ Open Motives for sickness presence among students at secondary school: a cross- sectional study in five European countries
}

\author{
Vegard Johansen ${ }^{1,2}$
}

To cite: Johansen V. Motives for sickness presence among students at secondary school: a cross-sectional study in five European countries. BMJ Open 2018;8:e019337. doi:10.1136/ bmjopen-2017-019337

- Prepublication history for this paper is available online. To view these files, please visit the journal online (http://dx.doi org/10.1136/bmjopen-2017019337).

Received 28 August 2017 Revised 4 December 2017 Accepted 7 December 2017
A) Check for updates

${ }^{1}$ Welfare and organisation, Eastern Norway Research Institute, Lillehammer, Norway

${ }^{2}$ Education and Lifelong Learning, Norwegian University of Science and Technology, Trondheim, Norway

Correspondence to Dr Vegard Johansen; vj@ostforsk.no

\section{ABSTRACT}

Objectives This article investigates various motives for sickness presence (SP) among students in secondary school.

Design Cross-sectional study.

Setting 25 secondary schools in Belgium, Estonia, Finland, Italy and Latvia.

Participants 5002 students between 16 and 19 years of age, $49 \%$ female.

Results Almost half of the students reported two or more incidents of SP. The study indicated that the practice of SP was mainly extrinsically motivated. The most often reported motives for SP were that absence could affect grades negatively, that important curriculum material was explained at the school and attendance requirements. Some students practising SP expressed intrinsic motivation, such as maintaining their social network and interest in what was learnt at school.

Conclusion The study investigated various motives for SP in secondary schools in five European countries. Extrinsic motivation for SP was more often reported than intrinsic motivation for SP. Multivariate analyses indicated that boys, students in vocational education, immigrants and students with low-educated parents more often reported intrinsic motivation for SP, while girls and students with high absence more often reported extrinsic motivation. There were also notable cross-country differences regarding reported motives for SP.

\section{INTRODUCTION}

Sickness presence (SP) refers to going to work despite illness. ${ }^{12}$ The concept has been a subject of increasing interest over the last two decades. One reason for studying SP is the association between health, sickness absence (SA) and SP. Cross-sectional studies have shown a strongly positive association between SA and SP, and longitudinal studies have shown that high SP is a risk factor for future SA and can cause serious health problems. ${ }^{2-8}$ A second reason for studying SP is the relationship with productivity. SP may reduce work capacity and influence the work performed. There is also a risk of infecting colleagues and customers. It is argued that
Strengths and limitations of this study

The sample was multinational and large.

- The response rate was high.

- The respondents could choose between eleven motives for sickness presence (SP), but the list was not exhaustive.

- The responses to questions about SP may suffer from recall bias.

managing SP effectively could be a competitive advantage. ${ }^{9-11}$

The prevalence of SP has been studied in many countries. Approximately 60\%-70\% of national samples of workers in the Netherlands, Sweden, Norway and Denmark reported SP in a year. ${ }^{12-14}$ Particular occupational groups have also been studied. For instance, more than $80 \%$ of physicians and general practitioners in Norway and the UK reported SP. ${ }^{15}{ }^{16}$ Investigations of determinants of SP have revealed that personal factors found to have an impact on SP include self-rated health, education level, gender, age, economic situation and social support. Work-related factors found to influence SP include occupational affiliation, job security/insecurity, work burden, working time arrangements, workplace culture, job satisfaction, control over work tasks and adjustment latitude. $^{13} 4$ 13-20

This article expands research on SP to comprise students in secondary schools in Belgium, Estonia, Finland, Italy and Latvia. One argument for investigating SP in schools is that high SP could be a possible indicator for future ill health. This corresponds with previous studies among workers on relations between SP and future ill health. ${ }^{25-8}$ A second argument for investigating SP is that attitudes towards absence and presence are something that might follow young people from school to the workplace. ${ }^{21} 22$ Third, previous studies 
among workers indicated that SP affected the quality and quantity of work, ${ }^{4-11}$ and it could be that SP also influenced school performance. Several associations and hypotheses may thus be tested, such as: an association between frequency/duration of SP and school performance (high SP could be negatively correlated with school performance), or an association between longterm health ${ }^{23}$ and school performance (the combination low SP and low SA could improve school performance) or an association between different motives for SP and school performance (some motives for SP might have a positive influence on school performance, while other motives for SP might influence school performance negatively).

A previous study investigated the prevalence of SP among students in secondary schools in Norway $(n=3040)$. Twenty-four per cent of students at $15-16$ years of age and $33 \%$ of students at 17-18 years of age reported high SP (four episodes or more). Girls, students with high absence rates, students with high levels of school motivation and students in vocational programmes reported high SP more often. ${ }^{24}$

Previous studies and models in working life suggest that motivation for SP might arise from outside or inside the individual. It is proposed that organisational/ work context factors and personal factors influence the choice between absence and presence when ill. ${ }^{3817}$ The main aim of the present study is to accumulate knowledge about the motives for practising SP among secondary school students.

The study distinguishes between intrinsic and extrinsic motives for SP. Intrinsic motivation refers to doing something because it is inherently interesting or enjoyable. Extrinsic motivation refers to doing something because it leads to a separable outcome. ${ }^{25}$ In self-determination theory (SDT), intrinsic motivation is an example of autonomous motivation. Autonomy involves acting with a sense of volition and having the experience of choice, such as students practising SP because they enjoy going to school. In contrast, controlled motivation involves acting with a sense of pressure. SDT proposes that extrinsic motivation can vary in the degree to which it is autonomous as opposed to controlled, ${ }^{26}$ for instance students practising SP because of school attendance requirements (less choice, very controlled) and students practising SP because crucial material/syllabus is explained at school (freedom of choice but with a sense of having to be at school). Several studies have provided evidence that autonomous motivation is associated with more positive attributes than controlling motivation. ${ }^{25-27}$

This study examines the occurrence of intrinsic and extrinsic motives underlying attending secondary school when ill, and it tests the association between such motives and a selection of background factors. The research question asked is: what are the main reported motives for SP in secondary schools in five European countries?

\section{METHODS}

The data used are from a student survey conducted in five countries in May and June in the school years 2016/2017. The selection of countries was a convenience sample, based on a positive response to the research project from the national education ministries. The chosen countries belong to various geographical regions: Northern Europe (Finland), Eastern Europe (Estonia and Latvia), Continental Europe (Belgium) and Southern Europe (Italy). The participants in the survey included students between 16 and 19 years of age. The data collection was part of a research project for the European Commission via the Erasmus+ programme. The assignor had no role in study design, in the collection, analysis and interpretation of the data, in the writing of the article or in the decision to submit for publication. The study was approved by the education ministries and school leadership in all five countries.

The survey was conducted at 25 schools, five schools in each country. The schools were selected by the ministries in 2015 and based on the following criteria: education programmes (vocational and general schools), size (small and large schools) and geography (schools in cities and the periphery). At each school, all students at one or two levels were invited to participate in the survey. The students were invited to the survey via an electronic letter with a link that directed them to the survey. Each school appointed one or two contact persons to distribute the electronic letter at the school and who were responsible for following up on the surveys. The school contact persons were also to ensure that students not attending school on the day of the survey were given an opportunity to answer the questionnaire on another day. Questionnaires were completed online at the school. Five thousand and two of the students responded, and the response rate was $\operatorname{good}(80 \%)$.

The questionnaire was designed specifically for this research project. It included questions about SP, absence, school performance, motivation, generic skills, entrepreneurial skills and background variables. The research team completed an English version of the questionnaire. This version was professionally translated to Finnish, Italian, Latvian, Flemish (Belgium), Estonian and Russian (second language in Estonia). The online questionnaires were tested by academics and practitioners in all countries. Pilot studies with students were conducted in all countries to address potential sources of bias; for example, the pilot studies gave advance warnings about practical challenges, and it ensured that the students understood all questions and that the questionnaire was meaningful for students in different countries. The respondents took about 20-25 min to fill out the questionnaire.

A reasonable period before the students were invited to the survey at school, an information letter about the research project was provided to students, parents and teachers. It explained the main purposes of the study and that answering the survey was voluntary. It also included contact information for the project leader, including 
email address and telephone number. Students who decided not to answer the survey did other school work.

Various approaches have been used to measure SP, such as duration (number of days), frequency (distribution of episodes) and impact on work performance (rating of the extent to which ill health has affected productivity). ${ }^{6}$ Several previous studies have measured frequency of SP. ${ }^{1-57131418}$ SP was measured by the following question: 'During the last school year, did you go to school despite feeling so ill that you should have stayed home sick?' SP was defined as attendance of this sort twice or more during the previous school year, which corresponds with the cut-off criteria used in earlier research. ${ }^{1-5}$ Two thousand four hundred and seventeen students reported two or more SP episodes, and for them it was mandatory to answer a series of statements about why they had attended school during illness. Thus, missing data was not a challenge for the dependent variables.

The 11 statements regarding SP were selected after a literature review of reasons for SP in working life, followed by group interviews with students to capture the school context. The cross-sectional survey that included questions about SP was part of a much larger research project. Another part of the project was group interviews with students from 10 out of 25 of the participating schools. School attendance and absence were topics in some of these interviews. Many students talked about various forms of attendance pressure in the interviews, while others mentioned more positive motives for SP. The question asked was 'Please agree or disagree with the following statements: I went to school even I was ill':

1. because I enjoy going to school

2. because I have great interest in what we learn at school

3. because going to school was beneficial for my health

4. because I want to maintain my social network

5 . because my pride depends on not being sick from school

6. because crucial material/syllabus is explained at school

7. because of school attendance requirements

8. because high school absence might negatively affect my chances to get a job/apprenticeship

9. because high school absence might negatively affect my grades

10. because I do not want to burden my classmates (eg, group work, lab work and so on)

11. Because of other reasons.

A 5-point Likert scale was used (1=strongly disagree to $5=$ strongly agree) on all statements. A principal component analysis (PCA) clustered the items into two components: one related to intrinsic motivation and one related to extrinsic motivation. A scale for intrinsic motivation was constructed by computing five items into one variable and then dividing by five to get the mean score for each respondent. A scale for extrinsic motivation was constructed by computing four items into one variable (statements 6-9) and then dividing by four to get the mean score for each respondent. Internal consistency was measured with Cronbach's alpha. As a sensitivity analysis, post hoc subgroup analysis confirmed that the items clustered into two components in all five countries.

Multivariate linear regression analysis was used to detect factors influencing motives for $\mathrm{SP}^{28}$ Regression can account for multiple confounders simultaneously, and 10 independent variables were included in the models. A correlation matrix for independent variables and dependent variables was also presented (Pearson's $r$, point biserial correlation and phi). The independent variables included in the model-building process were included since they had proven importance in previous studies of SP. Eighteen students did not answer all independent variables, and all cases with a missing value were deleted. Thus, the regression analyses included 2399 students:

- Gender: divided between male (reference category) and female ( $49 \%$ of the sample). Previous studies indicated no gender differences or that men more often practised SP, ${ }^{13417}$ but women more often reported that they practised SP because they did not want to burden their colleagues. ${ }^{13}$

- Age: scale variable from 16 years to 19 years of age (mean 16.9 years). A Norwegian study indicated that the level of SP was higher among students 17-18 years of age than students $15-16$ years of age. ${ }^{24}$

- Migratory status: divided between natives (reference category) and immigrants (comprising students born in other countries or with both parents born in other countries: $10 \%$ of the sample). A previous study indicated that immigrant workers reported more SP than natives. ${ }^{29}$

- Parents' education: divided between students who have parents with low educational attainment (reference category) and students who have parents with high educational attainment (bachelor degree or higher: $42 \%$ of the sample). Parental level of education had little impact on the frequency of SP in the previous study in secondary school. ${ }^{24}$

- Education programme: divided between academic/ technical (reference category) and vocational studies (35\% of the sample). An academic/technical studies programme leads to general university admission certification, while a vocational programme leads after school to a craft or journeyman's certificate followed by inservice training in an enterprise. In a previous study, students in vocational studies reported high SP more often, and this was related to low absence being an important criterion when employers allocated apprenticeships. ${ }^{24}$

- Country: divided between Italy (reference category) and Belgium, Estonia, Finland, and Latvia. The data were weighed such that the samples from each country carried the same influence $(20 \%)$. Before weighting, the distribution was: Latvia (37\%), Italy $(20 \%)$, Finland (16\%), Belgium (15\%) and Estonia $(12 \%)$. It is likely that there will be variations between 
Table 1 Distribution of students that agree or strongly agree with various motives for sickness presence in secondary school, \% of students (weighed results, $n=2417$ )

\section{Agree/strongly} agree

\begin{tabular}{|c|c|}
\hline $\begin{array}{l}\text { Because crucial material/syllabus is } \\
\text { explained at school }\end{array}$ & 68 \\
\hline $\begin{array}{l}\text { Because high school absence might } \\
\text { negatively affect my grades }\end{array}$ & 67 \\
\hline $\begin{array}{l}\text { Because of school attendance } \\
\text { requirements }\end{array}$ & 50 \\
\hline $\begin{array}{l}\text { Because I want to maintain my social } \\
\text { network }\end{array}$ & 41 \\
\hline $\begin{array}{l}\text { Because I do not want to burden my } \\
\text { classmates (eg, group work, lab work and } \\
\text { so on) }\end{array}$ & 40 \\
\hline $\begin{array}{l}\text { Because high school absence might } \\
\text { negatively affect my chances to get a job/ } \\
\text { apprenticeship }\end{array}$ & 40 \\
\hline $\begin{array}{l}\text { Because I have great interest in what we } \\
\text { learn at school }\end{array}$ & 40 \\
\hline Because I enjoy going to school & 26 \\
\hline $\begin{array}{l}\text { Because my pride depends on not being } \\
\text { sick from school }\end{array}$ & 22 \\
\hline $\begin{array}{l}\text { Because going to school was beneficial for } \\
\text { my health }\end{array}$ & 20 \\
\hline Because of other reasons & 14 \\
\hline
\end{tabular}

countries, relating, for instance, to various regulations or guidelines regarding school attendance.

- Level of absence: divided between students reporting high school absence (2weeks or more, $20 \%$ of the sample) and those with no or low absence. Some students with high absence might practise SP because of attendance requirement or to increase their chance of getting better grades. ${ }^{24}$

\section{RESULTS}

Forty-eight per cent of the students replied that they had gone to school twice or more even though it would have been reasonable to take sick leave during the last 12 months. Table 1 shows the proportion of students that reported agree or strongly agree to various statements about SP. Sixty-eight per cent reported SP because crucial material/syllabus was explained at school, $67 \%$ pointed out that high school absence could affect grades negatively and 50\% reported SP because of school attendance requirements. About $40 \%$ of the students reported SP to maintain their social network, interest in what they learn at school, not to burden classmates and to increase their chances of getting a job/apprenticeship. Some 20\%-26\% reported SP because they enjoyed going to school, that they were proud not to be absent and because of health benefits.

Table 2 presents the correlation matrix for independent variables and dependent variables, using a mix of different correlation coefficients. Table 3 presents the PCA on the items with orthogonal rotation (Varimax). Kaiser-MeyerOlkin values of 0.80 verified the sampling adequacy for the analysis, which is above the acceptable limit of 0.6. Bartlett's test of sphericity indicated that correlations between items were sufficiently large for PCA. Kaiser's criterion of 1 and the scree plot confirmed two components. Nine items were included in the final analysis, since 'Because I don't want to burden my classmates' loaded on both components. The table shows the factor loadings after rotation. The items that cluster together suggest that component 1 represents well-being at school and practising SP because it

Table 2 Correlation matrix for independent variables and dependent variables, using a mix of different coefficients: Pearson's $r$ (two variables on interval/ratio scale), point biserial correlation (dichotomous variable and interval/ratio scale variable) and phi (two dichotomous variables)

\begin{tabular}{|c|c|c|c|c|c|c|c|c|c|c|c|c|c|}
\hline & & 1 & 2 & 3 & 4 & 5 & 6 & 7 & 8 & 9 & 10 & 11 & 12 \\
\hline 1 & Female & 1 & -0.01 & 0.07 & 0.00 & -0.00 & 0.06 & -0.00 & 0.07 & -0.04 & 0.08 & -0.09 & 0.08 \\
\hline 2 & Age 16-19years & & 1 & 0.12 & 0.17 & -0.08 & 0.07 & 0.09 & -0.18 & -0.02 & 0.03 & 0.06 & -0.03 \\
\hline 3 & Vocational & & & 1 & -0.01 & -0.20 & -0.22 & -0.07 & 0.09 & 0.22 & 0.00 & 0.21 & 0.08 \\
\hline 4 & $\begin{array}{l}\text { Immigrant } \\
\text { (both parents born abroad) }\end{array}$ & & & & 1 & 0.02 & 0.16 & -0.03 & -0.11 & 0.03 & -0.03 & 0.08 & -0.00 \\
\hline 5 & Highly educated parent(s) & & & & & 1 & 0.12 & 0.03 & 0.06 & -0.12 & 0.00 & -0.12 & -0.00 \\
\hline 6 & Belgium & & & & & & 1 & -0.25 & -0.25 & -0.25 & -0.19 & -0.28 & -0.16 \\
\hline 7 & Estonia & & & & & & & 1 & -0.25 & -0.25 & 0.14 & -0.08 & 0.11 \\
\hline 8 & Latvia & & & & & & & & 1 & -0.25 & 0.05 & 0.04 & 0.07 \\
\hline 9 & Finland & & & & & & & & & 1 & 0.01 & 0.07 & 0.10 \\
\hline 10 & High school absence & & & & & & & & & & 1 & -0.05 & 0.12 \\
\hline 11 & Intrinsic motivated SP & & & & & & & & & & & 1 & 0.40 \\
\hline 12 & Extrinsic motivated SP & & & & & & & & & & & & 1 \\
\hline
\end{tabular}

SP, sickness presence. 
Table 3 Rotated factor loadings from principal component analysis with orthogonal rotation (Varimax) (weighed results, $\mathrm{n}=2417$ )

\section{Component 1 Component 2}

$\begin{array}{ll}\begin{array}{l}\text { Because I enjoy going to } \\ \text { school }\end{array} & 0.82 \\ \begin{array}{l}\text { Because going to school } \\ \text { was beneficial for my health }\end{array} & 0.81 \\ \begin{array}{l}\text { Because I have great } \\ \text { interest in what we learn at }\end{array} & 0.75 \\ \text { school } & \end{array}$

Because my pride depends 0.67

on not being sick from

school

\begin{tabular}{|c|c|c|}
\hline $\begin{array}{l}\text { Because I want to maintain } \\
\text { my social network }\end{array}$ & 0.60 & \\
\hline $\begin{array}{l}\text { Because high school } \\
\text { absence might negatively } \\
\text { affect my grades }\end{array}$ & & 0.83 \\
\hline $\begin{array}{l}\text { Because high school } \\
\text { absence might negatively } \\
\text { affect my chances to get a } \\
\text { job/apprenticeship }\end{array}$ & & 0.69 \\
\hline $\begin{array}{l}\text { Because of school } \\
\text { attendance requirements }\end{array}$ & & 0.69 \\
\hline $\begin{array}{l}\text { Because crucial material/ } \\
\text { syllabus is explained at } \\
\text { school }\end{array}$ & & 0.53 \\
\hline Eigenvalue & 3.41 & 1.46 \\
\hline$\%$ of variance & 32 & 23 \\
\hline Cronbach's alpha $(\alpha)$ & 0.80 & 0.69 \\
\hline
\end{tabular}

Kaiser-Meyer-Olkin $(\mathrm{KMO})=0.80$. Bartlett's test of sphericity $\chi^{2}$ (36) $=6156.95, P<0.001$.

is personally rewarding. Thus, these items relate to intrinsic motivation for SP. Component 2 represents various forms of attendance pressure and practising SP because of external rewards (get good grades, get a job and uphold attendance obligations). Thus, these items relate to extrinsic motivation for SP. Also worth noting, post hoc subgroup analysis confirmed that the items clustered into two components in all five countries.

Table 4 shows unstandardised coefficients, beta and $\mathrm{P}$ values (*) from multivariate linear regression models of variables relevant to the two types of motives. In the first model concerning SP in relation to intrinsic motivation, gender, education programme, migratory status, parental education, and country had a significant impact. In the second model concerning SP in relation to extrinsic motivation, gender, country and school absence had a significant impact.

\section{DISCUSSION}

The definition of SP used in this article does not ascribe motives to SP. It thus remains an empirical question whether students show up ill because of interest, obligations to classmates or attendance requirements. This study asked about the main reported motives for SP in secondary schools in five countries. The three most often reported motives for SP were extrinsic: crucial material/syllabus is explained at school, high school absence could affect grades negatively and school attendance requirements. Previous studies from working life indicate that SP resulting from attendance pressure negatively impacts employee health. ${ }^{125-8} \mathrm{In}$ this respect, it is somewhat worrying that so many students practising SP point to various forms of attendance pressure. In contrast to SP resulting from attendance pressure, intrinsically motivated SP could be beneficial for both the individual and the organisation, for instance, in helping with recovery to full health, given the potential benefits of remaining active. ${ }^{6} 13$

Students with high levels of school absence more often reported motives for SP relating to attendance pressure than students with no or low absence. A possible explanation for the positive association between high absence and extrinsic motivation for SP could be that students with a high absence may opt to attend school when sick to avoid sanctions. In line with this, a closer examination of the data showed that students with high absence practised SP because more absence could affect grades negatively or violate attendance requirements. Additionally, high absence could be indicative of students less academically motivated or satisfied, and these students would probably report extrinsic motives for SP more often. This is line with research on job satisfaction and absence, in which absence from work is thought to represent withdrawal from aversive work circumstances. ${ }^{30}$

There were also notable cross-country differences. Some of the differences between countries regarding extrinsic motivation could relate to different national regulations or school guidelines regarding school attendance. The strict absence regulations in Estonia and Latvia were reflected in the survey and group interviews. Estonia and Latvia had comparatively large proportions of students with high SP. Many Estonian and Latvian students reported that they practised SP because of school attendance requirements or to get (better) grades. In contrast, Belgian and Italian students referred less often to attendance requirements since there were no absence limits, while few students from these countries were concerned that absence could affect their chances of getting a job/apprenticeship. However, it was beyond the scope of the present study to investigate cross-country differences in detail.

Studies of SP in working life have demonstrated that intrinsic motives such as job satisfaction, joy at work and health benefits were important for SP. ${ }^{61318}$ In this study in the secondary school, few students reported SP because of pride, health benefits or because they enjoy school. Students expressing intrinsic motivation for SP often referred to social network and interest in school.

Girls had a significant higher score on extrinsic motives than boys, while boys had a significant higher score than 
Table 4 Linear regression of the variables influencing SP related to intrinsic motivation and SP related to extrinsic motivation (weighed results, $\mathrm{n}=2399$ )

\begin{tabular}{|c|c|c|c|c|}
\hline \multirow[b]{2}{*}{ Variables } & \multicolumn{2}{|c|}{ Intrinsic motivation } & \multicolumn{2}{|c|}{ Extrinsic motivation } \\
\hline & UC & $95 \% \mathrm{Cl}$ & UC & $95 \% \mathrm{Cl}$ \\
\hline Constant & $2.11^{\star *}$ & 1.45 to 2.76 & $2.74^{\star \star}$ & 2.23 to 3.24 \\
\hline Female & $-0.09^{\star \star}$ & -0.16 to 0.02 & $0.09^{\star *}$ & 0.04 to 0.14 \\
\hline Aged 16-19years & 0.03 & -0.00 to 0.06 & -0.01 & -0.04 to 0.02 \\
\hline Vocational & $0.23^{\star \star}$ & 0.15 to 0.31 & 0.03 & -0.03 to 0.10 \\
\hline Immigrant (both parents born abroad) & $0.20^{\star *}$ & 0.09 to 0.31 & -0.02 & -0.10 to 0.06 \\
\hline Highly educated parent(s) & $-0.10^{\star *}$ & -0.17 to 0.04 & -0.00 & -0.05 to 0.05 \\
\hline Belgium & $-0.36^{\star \star}$ & -0.46 to 0.26 & $-0.12^{\star \star}$ & -0.20 to 0.04 \\
\hline Estonia & $-0.17^{\star \star}$ & -0.27 to 0.07 & $0.24^{\star *}$ & 0.17 to 0.32 \\
\hline Latvia & 0.05 & -0.05 to 0.16 & $0.15^{\star *}$ & 0.07 to 0.24 \\
\hline Finland & 0.09 & -0.02 to 0.20 & $0.22^{\star *}$ & 0.13 to 0.31 \\
\hline High school absence & -0.03 & -0.11 to 0.05 & $0.10^{\star \star}$ & 0.04 to 0.16 \\
\hline Adjusted $\mathrm{R}^{2}$ & 0.10 & & 0.06 & \\
\hline
\end{tabular}

Unstandardised coefficients (UCs) are shown with $95 \% \mathrm{Cl}$ and $\mathrm{P}$ value $\left({ }^{* *}=\right.$ significant at $0.01,{ }^{*}=$ significant at 0.05$)$.

Reference categories: male; academic/technical; non-immigrant; low educated parents; Italy; no/low school absence.

$\mathrm{SP}$, sickness presence.

girls on intrinsic motives for SP. These findings could be an indication of differences in attitudes between boys and girls, for example, that it could be more important for more girls to have a low absence and to get good grades. Moreover, students in vocational programmes reported intrinsic motives for SP more often than students in academic/technical programmes. The result is in line with the previous study about SP in the secondary school that indicated differences between education programmes $^{24}$ and with previous education studies indicating that students find vocational studies both easier and more interesting than academic studies.

The associations between immigration status and parents' educational level with intrinsic motivation for SP were surprising. Immigrants and students with low-educated parents had higher scores on intrinsic motivation for SP, although natives and students with highly educated parents generally experience better school mastery and school well-being. ${ }^{31}{ }^{32}$ In the sample, immigrants and students with low-educated parents had lower school performance, but they were equally motivated and happy at school as non-immigrants and those with highly educated parents. Moreover, a closer examination showed that immigrants and students with low-educated parents were particularly overrepresented among those reporting SP because of health benefits, pride and enjoyment of school.

The strengths of this study are that it is multinational, has a large sample (5002 students) with a high response rate and that it provides an opportunity to analyse many variables of relevance to SP. There are nevertheless many limitations to the findings, as regards the design and selection of schools, the items and the use of self-reported data. First, the cross-sectional design means that it is not possible to trace causal relationships or to discuss the long-term consequences of intrinsically and extrinsically motivated SP. Although the selection of participating schools was based on a diverse distribution, the low number of schools from each country could be considered a weakness. Second, the distinction between act and impact of SP is relevant, such that the study is limited by only assessing the frequency of SP, without taking account of other aspects such as duration of SP and the estimated impact of SP on productivity. ${ }^{6}$ Questions about SP might have been influenced by recall bias. The list of motives was not exhaustive, and many other statements could have been included. Even though parental influence was not discussed much in the group interviews concerning absence and presence, attendance pressure from parents or willingness to conform to parental expectations should have been included in the list of statements. Third, in research on SP, it is difficult not to use self-reported data, because it is the individual who knows if he or she has been present or not during sickness. Many of the previous studies used similar questions to measure SP. ${ }^{1-8} 1824$ The use of self-reported data also makes it likely that the study may suffer from common method bias. Common method biases arise from characteristics of the items, the context of items and their location in the questionnaire, the measurement context and matters related to the respondent and his/her behaviour. ${ }^{33}$

This large-scale multinational study has contributed to the existing literature by investigating extrinsic and intrinsic motives for SP among students in secondary school. The study confirms the finding from a previous Norwegian study ${ }^{24}$ that many secondary school students practise SP, and it suggests that the practice of SP was mainly extrinsically motivated. Like adult workers, it 
seems likely that secondary school student in different across countries practise SP. Still, the discussion of study weaknesses questions to what extent research findings concerning motives for SP are generalisable. An important threat to the external validity of the study is, for instance, the selection of schools that does not ensure that the sample obtained is representative of the population (students in upper secondary school). The test of the external validity is replication, and it would be exciting if the study could be conducted again in the same and/or other countries. To understand and explain differences in motives between various groups of students, research with a qualitative design is necessary. Longitudinal studies are needed to make conclusions about the consequences of high SP for students. It is, for instance, possible to think that intrinsically motivated SP could have a positive impact on future school performance and future health, while SP related to extrinsic motives and attendance pressure could have a negative influence on school performance and cause future ill health.

Contributors Research professor VJ is the author of the manuscript. He designed and monitored the data collection, cleaned and analysed the data and wrote the paper.

Funding This work was supported by the European Commission via the Erasmus+ programme.

Competing interests None declared.

Ethics approval The study was ethically approved by the Data Protection Official for Research (Norwegian Social Science Data Services).

Provenance and peer review Not commissioned; externally peer reviewed.

Data sharing statement № additional data available.

Open Access This is an Open Access article distributed in accordance with the Creative Commons Attribution Non Commercial (CC BY-NC 4.0) license, which permits others to distribute, remix, adapt, build upon this work non-commercially, and license their derivative works on different terms, provided the original work is properly cited and the use is non-commercial. See: http://creativecommons.org/ licenses/by-nc/4.0/

(C) Article author(s) (or their employer(s) unless otherwise stated in the text of the article) 2018. All rights reserved. No commercial use is permitted unless otherwise expressly granted.

\section{REFERENCES}

1. Hansen CD, Andersen JH. Sick at work-a risk factor for long-term sickness absence at a later date? J Epidemiol Community Health 2009;63:397-402.

2. Bergström G, Bodin L, Hagberg J, et al. Sickness presenteeism today, sickness absenteeism tomorrow? A prospective study on sickness presenteeism and future sickness absenteeism. J Occup Environ Med 2009;51:629-38.

3. Aronsson G, Gustafsson K, Dallner M. Sick but yet at work. An empirical study of sickness presenteeism. J Epidemiol Community Health 2000;54:502-9.

4. Böckerman P, Laukkanen E. What makes you work while you are sick? Evidence from a survey of workers. Eur $J$ Public Health 2010;20:43-6.

5. Taloyan M, Aronsson G, Leineweber C, et al. Sickness presenteeism predicts suboptimal self-rated health and sickness absence: a nationally representative study of the Swedish working population. PLoS One 2012;7:e44721.
6. Whysall Z, Bowden J, Hewitt M. Sickness presenteeism: measurement and management challenges. Ergonomics 2017:1-14.

7. Kivimäki M, Head J, Ferrie JE, et al. Working while ill as a risk factor for serious coronary events: the Whitehall II study. Am J Public Health 2005;95:98-102.

8. Gustafsson K, Marklund S. Consequences of sickness presence and sickness absence on health and work ability: a Swedish prospective cohort study. Int J Occup Med Environ Health 2011;24:153-65.

9. Collins JJ, Baase CM, Sharda CE, et al. The assessment of chronic health conditions on work performance, absence, and total economic impact for employers. J Occup Environ Med 2005;47:547-57.

10. Hemp P. Presenteeism: at work-but out of it. Harv Bus Rev 2004;82:49-58

11. Lovell V. No time to be sick: Why everyone suffers when workers don't have paid sick leave. Washington, DC: Institute for Women's Policy Research, 2004.

12. Vroome E. Prevalence of sickness absence and 'presence'. http:// eurofound.europa.eu/ewco/2006/07/NL0607019l.htm (accessed 10 Aug 2017)

13. Johansen V, Aronsson G, Marklund S. Positive and negative reasons for sickness presenteeism in Norway and Sweden: a cross-sectional survey. BMJ Open 2014;4:e004123.

14. Hansen $\mathrm{CD}$, Andersen JH. Going ill to work-what personal circumstances, attitudes and work-related factors are associated with sickness presenteeism? Soc Sci Med 2008;67:956-64.

15. McKevitt C, Morgan M, Dundas R, et al. Sickness absence and 'working through' illness: a comparison of two professional groups. J Public Health Med 1997;19:295-300.

16. Rosvold EO, Bjertness E. Physicians who do not take sick leave: hazardous heroes? Scand J Public Health 2001;29:71-5.

17. Johns G. Presenteeism in the workplace: A review and research agenda. J Organ Behav 2010;31:519-42.

18. Marklund S, Aronsson G, Johansen V, et al. Previous sickness presence among long-term sick-listed in Norway and Sweden: A retrospective study of prevalence and self-reported reasons. Int $J$ Soc Welf 2015;24:376-87.

19. Claes R. Employee correlates of sickness presence: A study across four European countries. Work Stress 2011;25:224-42.

20. Johansson G, Lundberg I. Adjustment latitude and attendance requirements as determinants of sickness absence or attendance. Empirical tests of the illness flexibility model. Soc Sci Med 2004;58:1857-68.

21. Eagly AH, Chaiken S. The psychology of attitudes. Fort Worth, TX: Harcourt Brace Jovanovich, 1993.

22. Glasman LR, Albarracín D. Forming attitudes that predict future behavior: a meta-analysis of the attitude-behavior relation. Psychol Bull 2006;132:778-822.

23. Aronsson G, Blom V. Work conditions for workers with good longterm health. Int J Workplace Health Manag 2010;3:160-72.

24. Johansen V. Sick and still at school: an empirical study of sickness presence among students in Norwegian secondary school. BMJ Open 2015;5:e008290

25. Ryan RM, Deci EL. Intrinsic and Extrinsic Motivations: Classic Definitions and New Directions. Contemp Educ Psychol 2000;25:54-67.

26. Gagné M, Deci EL. Self-determination theory and work motivation. $J$ Organ Behav 2005;26:331-62.

27. Deci EL, Koestner R, Ryan RM. A meta-analytic review of experiments examining the effects of extrinsic rewards on intrinsic motivation. Psychol Bull 1999;125:627-68.

28. Field A. Discovering statistics using IBM SPSS statistics. London: Sage Publications, 2013.

29. Agudelo-Suárez AA, Benavides FG, Felt E, et al. Sickness presenteeism in Spanish-born and immigrant workers in Spain. BMC Public Health 2010;10:791.

30. Johns G. Contemporary research on absence from work: Correlates, causes, and consequences. International Review of Industrial and Organizational Psychology 1997;12:115-74.

31. Hattie JAC. Visible learning: a synthesis of over 800 meta-analyses relating to achievement. New York: Routledge, 2009.

32. OECD. Immigrant students at school: Easing the journey towards integration. Paris: OECD.

33. Podsakoff PM, MacKenzie SB, Podsakoff NP. Sources of method bias in social science research and recommendations on how to control it. Annu Rev Psychol 2012;63:539-69. 